\title{
IMMUNOHISTOCHEMICAL STUDY OF CONJUNCTIVA-ASSOCIATED LYMPHOID TISSUE IN PIGLETS AND PIGS
}

\author{
Almazbek Irgashev ${ }^{1 *}$, Zakiia Kalandarova ${ }^{1}$, Svetlana Ishenbaeva $^{1}$, Eliza Asanova $^{2}$, Tugolbai Tagaev ${ }^{3}$, Yethindra \\ Vityala $^{4}$, Srilaxmi Vityala ${ }^{5}$ \\ Received 12 November 2020, revised 20 May 2021
}

\begin{abstract}
In order to identify and study the distribution of T lymphocytes, B lymphocytes, and cell proliferation in the porcine conjunctiva-associated lymphoid tissue (CALT), an immunohistochemical study was carried out of the eyelids in clinically healthy piglets and pigs. Using polyclonal rabbit antiserum against CD3 (PAP method), mouse monoclonal antibody against CD79 $\alpha$ (ABC method), and mouse monoclonal antibody against PCNA (PAP method), T lymphocytes, B lymphocytes, and the proliferation of lymphoid cells in the conjunctiva of formalin-fixed, paraffin-embedded eyelids of piglets and pigs were immunohistochemically identified. Results revealed age-dependent quantitative changes in $T$ and $B$ lymphocytes and lymphoid follicles in piglets and pigs. The immunohistochemical and quantitative data obtained showed that the conjunctiva of 5 day-old piglets had T lymphocytes, while B lymphocytes were absent. Two-month-old piglets had both $T$ and $B$ lymphocytes in the subepithelial tissue, but the number of T lymphocytes predominated. In 6 and 12 monthold pigs, in addition to $T$ and $B$ lymphocytes, the conjunctiva had functioning lymphoid follicles with $T$ and $B$ zones. In the germinal center of some lymphoid follicles, the proliferation of lymphoblasts was recognizable. The results obtained can be used to study the role of CALT in the diseases of the eye and par ocular tissues in piglets and pigs.
\end{abstract}

Key words: Conjunctiva-associated lymphoid tissue, Immuno-histochemistry, Piglets, Pigs.

\section{INTRODUCTION}

Several studies have previously established that the human conjunctiva has lymphoid tissue and consists of $\mathrm{T}$ and B lymphocytes, CD8- and CD4-positive T cells (Knop and Knop 2008, Steven et al. 2008, Bose et al. 2017). In parallel with the study of human conjunctiva, similar studies have been conducted in the laboratory, domestic, and wild animals.

Immunohistochemical studies of the conjunctiva in various animal species showed the following results: the rabbit conjunctival lymphoid tissue consisted of $\mathrm{T}$ and $\mathrm{B}$ lymphocytes (Franklin and Remus 1984), the mouse conjunctiva consisted of CD4-, CD8-, and S-100-positive cells (Sakimoto et al. 2002). The baboon (Papio anubis) conjunctival lymphoid tissue had CD4-positive T lymphocytes and B lymphocytes (Astley et al. 2003). The conjunctivas of Peromyscus maniculatus (species of new world rodents) consisted of B and T cells (Astley et al. 2007).

An immunohistochemical study of cattle CALT revealed that $\mathrm{CD} 4+$ and $\mathrm{CD} 8+\mathrm{T}$ cells were detected in the interfollicular and subepithelial regions of the CALT. CD4+ T cells were localized in the lower parts of the follicles, in the interfollicular and subepithelial regions,

\footnotetext{
${ }^{1}$ Department of Veterinary Sanitary Expertise, Histology and Pathology, ${ }^{2}$ Department of Biotechnology and Chemistry, Faculty of Veterinary Medicine and Biotechnology, Kyrgyz National Agrarian University named after K. I. Skryabin (KNAU), Bishkek-720005, Kyrgyzstan.

${ }^{3}$ Department of Public Health and Healthcare, I.K. Akhunbaev Kyrgyz State Medical Academy, 92, Akhunbaev street, Bishkek-720020, Kyrgyzstan. ${ }^{4}$ Department of Pathology, International Higher School of Medicine, International University of Kyrgyzstan, $1 F$, Intergelpo street, Bishkek-720054, Kyrgyzstan.

${ }^{5}$ College of fishery science, Pebbair, Wanaparthy-509104, Telangana, India.

*Corresponding author. e-mail: yethindravityala10@gmail.com
} 
and infrequently in the germinal centers and the CD8+ T lymphocytes were mainly in the subepithelial and interfollicular regions (Bayraktaroglu and Asti 2009).

For the immunohistochemical study of pig tissues aimed at identifying the main immunocompetent cells on histo-sections, it is necessary to know the distribution of different cells in formalin-fixed, paraffin-embedded tissues with several primary antibodies, including antiCD3 and anti-CD79 $\propto$ (Chianini et al. 2001, Tanimoto and Ohtsuki 1996). Anti-CD3 and anti-CD79 $\propto$ monoclonal antibodies strongly reacted with cells located in the $\mathrm{T}$ cell and $\mathrm{B}$ cell areas, respectively, and showed specificity for $\mathrm{T}$ and $\mathrm{B}$ cells in pig tissues $\mathrm{CD} 79 \propto$ (Chianini et al. 2001, Tanimoto and Ohtsuki 1996). However, the distribution of $\mathrm{T}$ and $\mathrm{B}$ lymphocytes in CALT in healthy piglets and pigs have not been studied.

The present study aimed to describe the age-dependent distribution of $\mathrm{T}$ and $\mathrm{B}$ lymphocytes and cell proliferation in the porcine CALT using immuno-histochemical methods.

\section{MATERIALS AND METHODS}

The experiment on piglets and pigs, including all procedures of this study were approved by Scientific and Ethical Committee of Faculty of Veterinary Medicine and Biotechnology of Kyrgyz National Agrarian University named after K.I. Skryabin (Protocol No. 4 dated 22.12.2017). Using polyclonal rabbit antiserum against CD3 (PAP method), mouse monoclonal antibody against $\mathrm{CD} 79 \propto(\mathrm{ABC}$ method), and mouse monoclonal antibody against PCNA (PAP method), we immunohistochemically identified T lymphocytes, B lymphocytes, and the proliferation of lymphoid cells in the conjunctiva of formalin-fixed, paraffin-embedded eyelids of piglets and pigs.

\section{Immunohistochemical studies}

The conjunctivas from the lower and upper eyelids of 12 healthy Large White Pigs were obtained from a slaughterhouse near Bishkek city (Kyrgyzstan). A total of 24 eyelids of these 12 piglets and pigs (three heads of 5-7-day-old suckling pigs, three heads of 2-month-old pigs, three heads of 6-month-old pigs, and three heads of 12-month-old pigs) were examined. Together with conjunctivitis from both eyelids, lymph nodes, spleens were harvested from the same piglets and pigs. Tissue specimens were fixed in corrected buffered formaldehyde ( $\mathrm{pH} 7.4)$, processed and subsequently embedded in paraffin wax. Then, 5 - $\mu$ m-thick paraffin sections were cut. The following histological and immunohistochemical methods were used. Sections were stained using hematoxylin and eosin ( $\mathrm{H} \& \mathrm{E})$ to exclude any pathology in the conjunctiva. For the demonstration of $\mathrm{T}$ lymphocytes, B lymphocytes and cell proliferation, the following primary antibodies and methods were used: Polyclonal rabbit antiserum against CD3 (Code Nr. A 0452, Dako) (PAP method) to demonstrate $T$ lymphocytes; mouse monoclonal antibody against CD79 $\propto-$ Purified (Clone HM 57, Acris) (ABC method) to demonstrate B lymphocytes; mouse monoclonal antibody against PCNA (Clone PC 10, Code Nr. 0879, Dako) (PAP method) for the demonstration of cell proliferation. Substrate: $0.05 \% 3,3^{\prime}-$ diaminobenzidine tetrahydrochloride dihydrate (DAB) (Fluka, cat. Nr. 32750), $0.1 \mathrm{~m}$ imidazole/HCl buffer, $\mathrm{pH}$ 7.08, and $0.01 \% \mathrm{H}_{2} \mathrm{O}_{2}$ (Merck).

\section{Cell counting}

Microscopically, the number of T lymphocytes, B lymphocytes, and proliferating cells, both in the subepithelial tissue of the conjunctiva and in the T- and B-zones of the lymphoid nodules, was calculated in 10

Table 1. The number of T lymphocytes, B lymphocytes and lymphoblasts in CALT in piglets and pigs [Mean \pm standard deviation $(M \pm m)]$.

\begin{tabular}{llllll}
\hline $\begin{array}{l}\text { Age of piglets/ } \\
\text { pigs }(\mathbf{M} \pm \mathbf{m})\end{array}$ & $\begin{array}{l}\text { No. of } \mathbf{T} \\
\text { lymphocytes in } \\
\text { subepithelial } \\
\text { tissue of the } \\
\text { conjunctiva }\end{array}$ & $\begin{array}{l}\text { No. of B } \\
\text { lymphocytes in } \\
\text { subepithelial } \\
\text { tissue of the } \\
\text { conjunctiva }\end{array}$ & $\begin{array}{l}\text { T-zone } \\
\text { of CALT }\end{array}$ & $\begin{array}{l}\text { B-zone } \\
\text { of CALT }\end{array}$ & $\begin{array}{l}\text { No. of } \\
\text { lymphoblasts in } \\
\text { the lymphoid } \\
\text { follicles of } \\
\text { CALT }\end{array}$ \\
\hline 5-day/piglets & $4.07 \pm 0.41$ & - & - & - & - \\
2-month/piglets & $9.70 \pm 1.35$ & $5.30 \pm 0.90$ & - & - & - \\
6-month/pigs & $20.43 \pm 2.05$ & $12.11 \pm 1.00$ & $48.61 \pm 8.04$ & $25.24 \pm 2.48$ & $23.64 \pm 3.49$ \\
12-month/pigs & $15.35 \pm 1.25$ & $11.04 \pm 0.96$ & $46.64 \pm 7.23$ & $26.74 \pm 2.47$ & $21.63 \pm 2.43$ \\
\hline
\end{tabular}




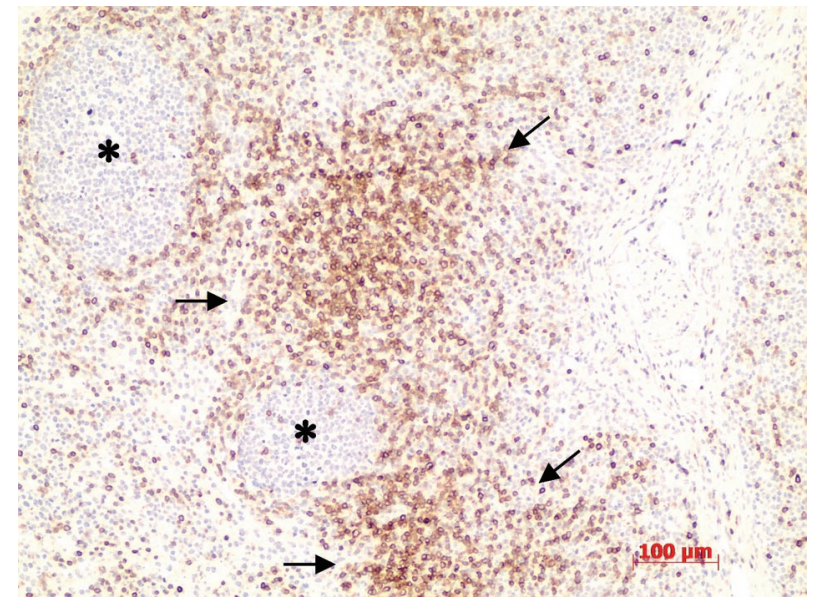

Fig. 1. Photomicrograph showing the T lymphocytes (arrows) localized in the paracortical (T) zone of the lymph node in the 6-month-old pig.

[Lymphoid follicles were not brown colored (asterisks). Anti-CD3 antibody (PAP method)-Haematoxylin counterstain x $100($ Bar $=100 \mu)]$..

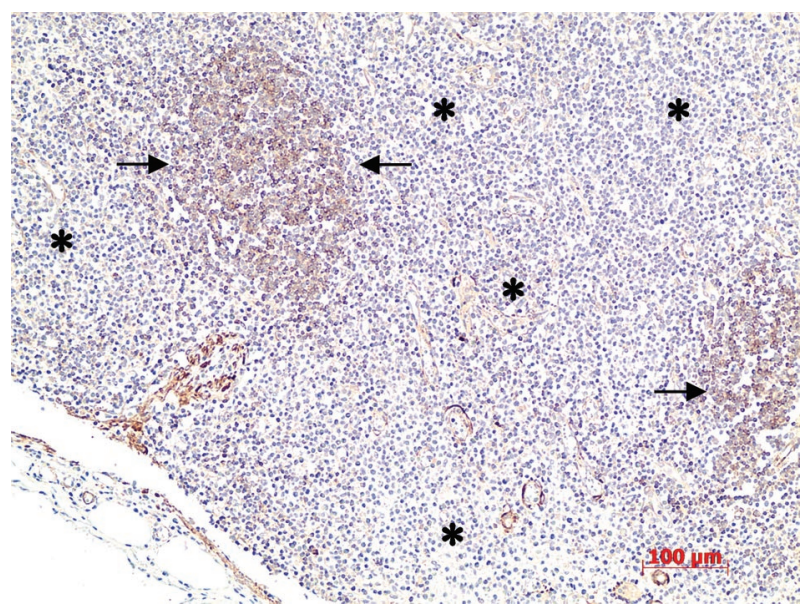

Fig. 2. Photomicrograph showing the B lymphocytes (arrows) localized in the lymphoid follicles (B zone) of the lymph node in the 6-month-old pig.

[The paracortical (T) zone was not brown colored (asterisks). Anti-CD79 $\propto$ antibody (ABC method)Haematoxylin counterstain $\mathrm{x} 100(\mathrm{Bar}=100 \mu)]$.

fields of view of the microscope with a magnification $\times 1000$. The obtained data are presented as the mean \pm standard deviation $(\mathrm{M} \pm \mathrm{m})$ using Excel. XLSTAT v2020.1 (Microsoft, Addinsoft, Paris, France).

\section{RESULTS AND DISCUSSION}

Immunohistochemical detection of $T$ and $B$ lymphocytes, cell proliferation in the lymph node and spleen

Before studying the main immune-component cells of CALT in pigs, we first microscopically examined the

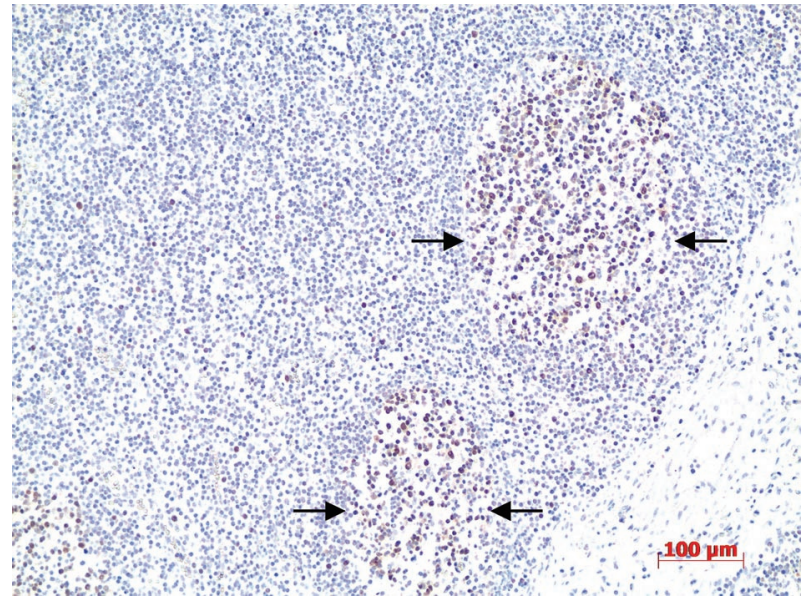

Fig. 3. Photomicrograph showing brown stained blast cells (arrows) in the germinal center of the lymphoid follicles of the lymph node in the 6-month-old pig. [Anti-PCNA antibody (PAP method)-Haematoxylin counterstain x $100(\mathrm{Bar}=100 \mu)]$.

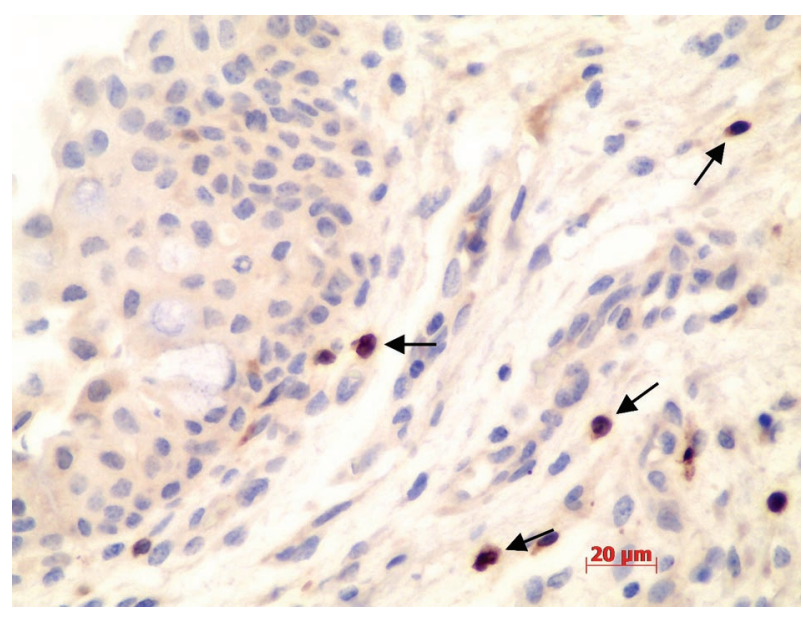

Fig. 4. Photomicrograph showing the T lymphocyte (arrow) scattered in the subepithelial tissue of conjunctiva of 5-day old piglets.

[Anti-CD3 antibody (PAP method)-Haematoxylin counterstain $\times 400($ Bar $=20 \mu)]$.

staining results of $\mathrm{T}$ - and $\mathrm{B}$-zone cells as well as lymphoblasts in the germinal centers of the lymph nodes and spleen with anti-CD3, anti-CD79 $\propto$, anti-PCNA primary antibodies.

Anti-CD3 antibody strongly stained the paracortical (T-) zone of the lymph node cortex (Fig. 1) and the periarterial (T-) zone of the white pulp of the spleen and anti-CD79 $\propto$ antibody - lymphoid follicles (B-zones) of the cortex of lymph nodes (Fig. 2) and white pulp of the spleen. Whereas anti-PCNA primary antibody clearly stained blast cells in B zones of the lymph nodes (Fig. 3) and spleen. 


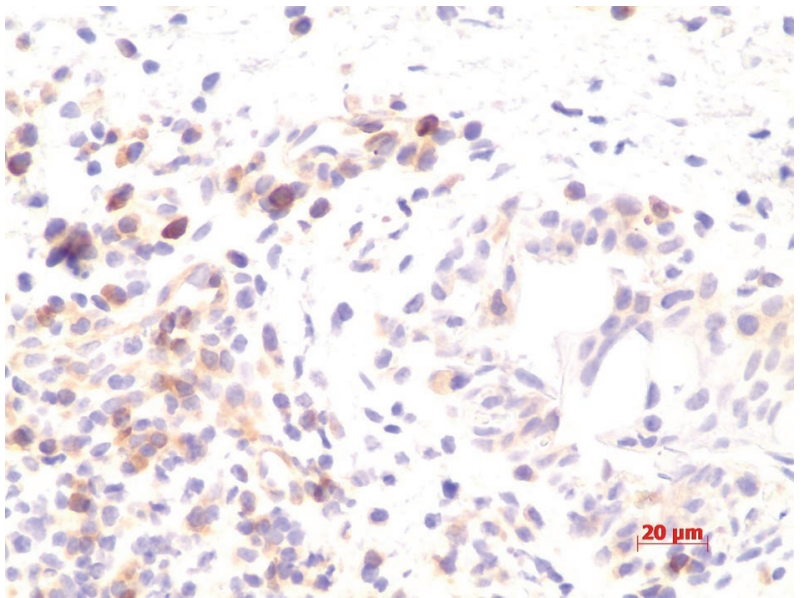

Fig. 5. Photomicrograph showing numerous B lymphocytes in the subepithelial tissue of conjunctiva of 2-month-old piglets.

[Anti-CD79 $\propto$ antibody (ABC method)-Haematoxylin counterstain $\mathrm{x} 400(\mathrm{Bar}=20 \mu)]$.

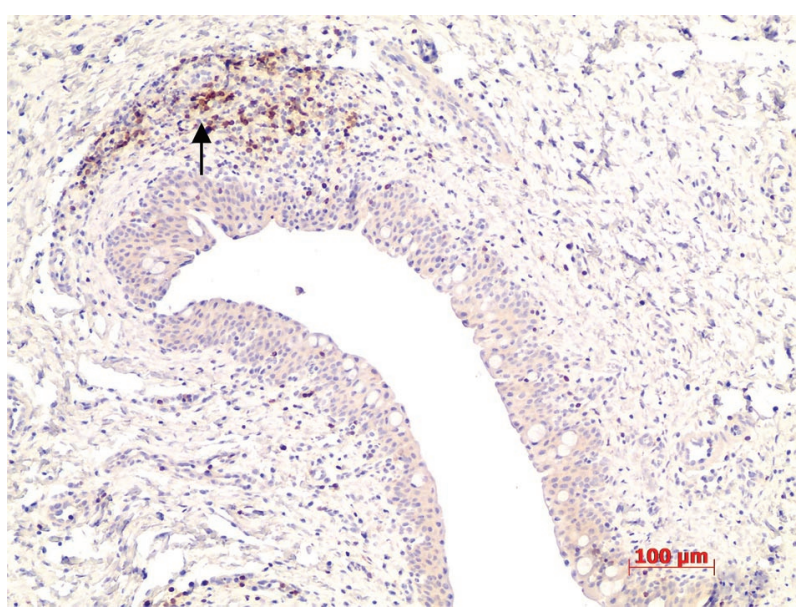

Fig. 6. Photomicrograph showing numerous $T$ lymphocytes (arrow) in the subepithelial tissue of conjunctiva of 2-month-old piglets.

[Anti-CD3 antibody (PAP method)-Haematoxylin counterstain $\mathrm{x} 100(\mathrm{Bar}=100 \mu \mathrm{m})]$.

\section{Immunohistochemical study of CALT in pigs}

In 5-day-old piglets, the subepithelial connective tissue of palpebral conjunctiva contained scattered $\mathrm{T}$ lymphocytes (Fig. 4), whereas B lymphocytes were absent. Within the conjunctival stratified epithelium, there were isolated intraepithelial T lymphocytes. In 2-monthold pigs, the subepithelial tissue of the conjunctiva had numerous $\mathrm{T}$ and $\mathrm{B}-\mathrm{lym}$ phocytes. Within the conjunctival stratified epithelium, there were intraepithelial $\mathrm{T}$ lymphocytes. Additionally, there was a small accumulation of both B lymphocytes (Fig. 5) and T lymphocytes (Fig. 6) around the vessels and in the

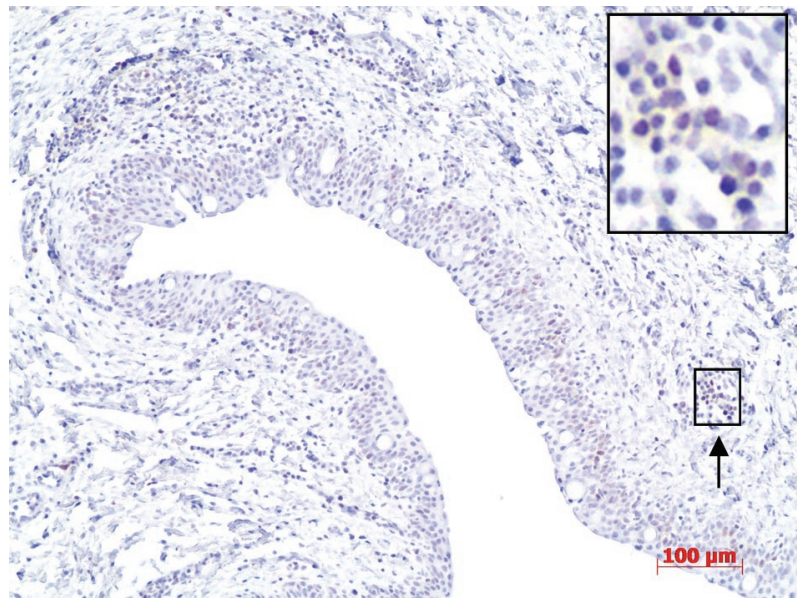

Fig. 7. Photomicrograph showing proliferating lymphoid cells (arrow) in the subepithelial tissue of the conjunctiva of 2-month-old piglets.

[Anti-PCNA antibody (PAP method)-Haematoxylin counterstain $\mathrm{x} 100(\mathrm{Bar}=100 \mu \mathrm{m})]$.

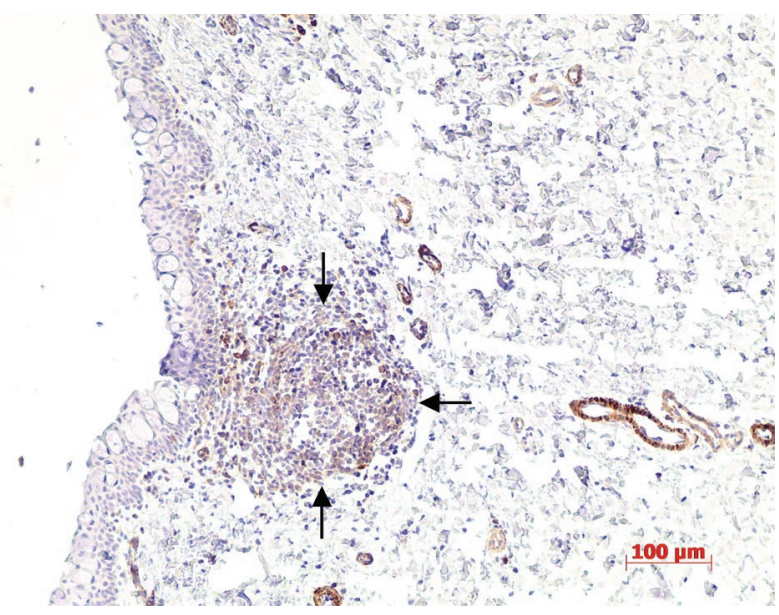

Fig. 8. Photomicrograph showing the lymphoid follicle containing B lymphocytes (B-zone) (arrows) in the subepithelial tissue of conjunctiva of the 6-month-old pig.

[Anti-CD79 $\propto$ antibody (ABC method)-Haematoxylin counterstain x $100($ Bar $=100 \mu)]$.

subepithelial tissue of the conjunctiva. The proliferation of lymphoid cells in the subepithelial tissue of the conjunctiva was noted (Fig. 7). In the 6- and 12-monthold pigs, the subepithelial tissue of palpebral conjunctiva contained scattered T and B-lymphocytes. The lymphoid follicles generally consisted of B lymphocytes, forming B-zones of CALT (Fig. 8). The proliferation of lymphoblasts was noted in the germinal centers of the lymphoid follicles (Fig. 9). The majority of T lymphocytes were located around the lymphoid follicles and formed T-zones (Fig. 10). CD3+ T lymphocytes also occurred in 


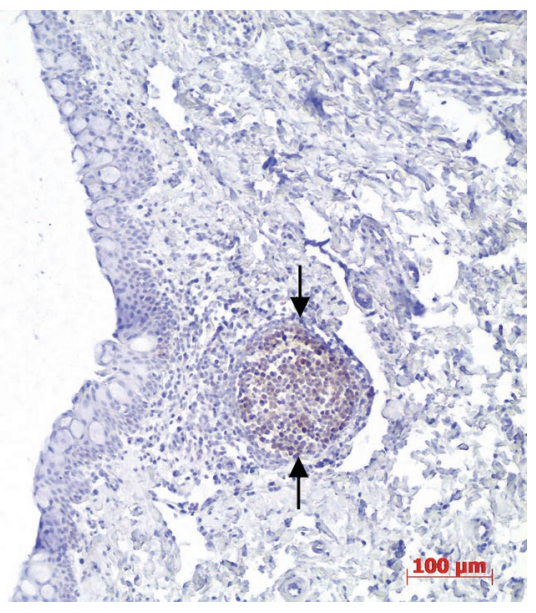

Fig. 9. Photomicrograph showing the proliferation of lymphoid cells (arrows) in the germinal center of the lymphoid follicle of the conjunctiva of 6-month-old pig. [Anti-PCNA antibody (PAP method)-Haematoxylin counterstain $\mathrm{x} 100(\mathrm{Bar}=100 \mu \mathrm{m})]$.

the germinal center of the follicles and had direct contact with the conjunctival epithelium. The lymphoid follicles had direct contact with the epithelium of the conjunctiva (follicle-associated epithelium) as shown in Fig. 8 and Fig. 10.

The quantitative changes in T lymphocytes, B lymphocytes and blast cells in the subepithelial tissue of the conjunctiva and in T- and B-zones of CALT based on the age of the pig (Table 1).

Similar to Chianini et al. (2001), we used the following primary antibodies for the identification of the subpopulation of immunocompetent cells in CALT of pigs, including eyelids: anti-CD3, anti-CD79 $\propto$, and antiPCNA in formalin-fixed, paraffin-embedded lymphoid tissues (lymph nodes and spleen) of pigs. Before studying the localization of T, B lymphocytes, and lymphoblasts in porcine CALT, we earlier examined microscopically the staining results of $\mathrm{T}$ - and B-zone cells as well as lymphoblasts in the germinal centers of the lymph nodes and spleen with the above antibodies. In histo-slides of the lymph nodes and spleen, anti-CD3 and anti-CD79 $\propto$ primary antibodies were used to stain cells located in $\mathrm{T}$ cell and B cell areas, respectively. The results of our study also confirm the data obtained through studies of Tanimoto and Ohtsuki (1996) and Chianini et al. (2001) on the specificity of the primary antibodies, anti-CD3 and anti-CD79 $\propto$, for the detection of T lymphocytes and B lymphocytes in formalin-fixed, paraffin-embedded tissues of pigs. Anti-PCNA antibody was used to detect proliferating cells and it identified immunoblasts in the

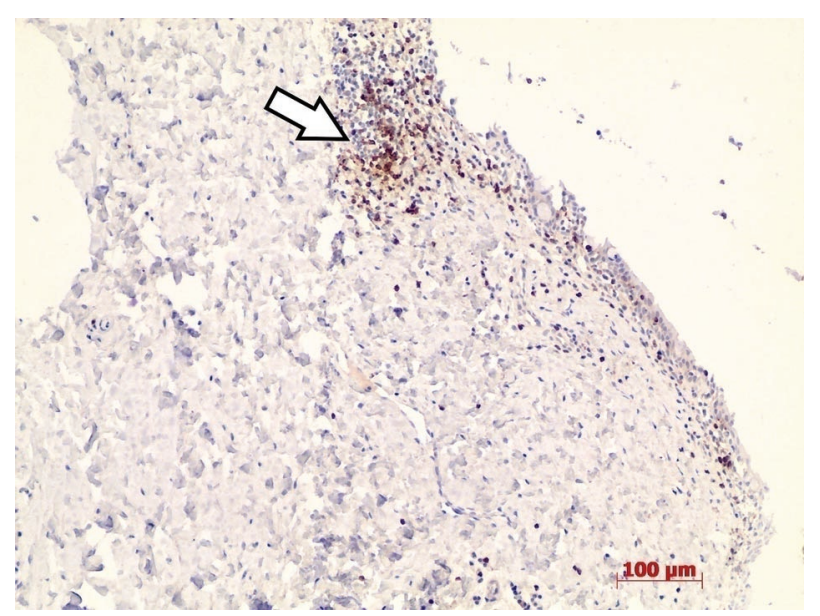

Fig. 10. Photomicrograph showing T lymphocytes around a small lymphoid follicle (T-zone) (arrow) of the conjunctiva of the 12-month-old pig.

[Anti-CD3 antibody (PAP method)-Haematoxylin counterstain $\mathrm{x} 100(\mathrm{Bar}=100 \mu \mathrm{m})$.

germinal centers of the lymphoid follicles of the lymph nodes and spleen.

Next, we studied the localization of T, B lymphocytes, and lymphoblasts in CALT. As indicated in the literature, immunohistochemical studies were used to detect the presence of T lymphocytes and B lymphocytes in CALT in humans (Knop and Knop 2008, Steven et al. 2008, Bose et al. 2017), as well as in rabbits (Franklin and Remus 1984), monkeys (Astley et al. 2003), rodents (Astley et al. 2007), and cattle (Bayraktaroglu and Asti 2009). However, our studies revealed that the cellular composition of CALT in pigs is also represented by $\mathrm{T}$ and $\mathrm{B}$ lymphocytes, confirming the data of other studies on the presence of $\mathrm{T}$ and $\mathrm{B}$ lymphocytes in CALT in other animal species as well as in humans.

However, in humans and the above-studied animals, the change in the number of basic immunocompetent cells based on age has not been studied. Therefore, in our study, we demonstrated the changes in the number of $\mathrm{T}$ and $\mathrm{B}$ lymphocytes based on the age of the pigs. The use of the anti-PCNA antibody showed the proliferation of lymphoblasts in the germinal center of separate lymphoid follicles. The number of T, B lymphocytes and blast cells in the conjunctiva showed quantitative changes in the above cells in CALT, depending on the age of pigs. In 2month-old pigs, the number of $\mathrm{T}$ and $\mathrm{B}$ lymphocytes in the subepithelial tissue of conjunctiva was higher than that in the 5-day old piglets. The number of T lymphocytes increased up to 6 months of age, following which there was a slight decrease. B lymphocytes appeared only from 
2 months of age and then their number increased. At 6 months of age, T-zones and B-zones of CALT was fully formed and they continued to function fully. The number of proliferating blast cells in the lymphoid follicles of CALT at both 6 and 12 months of age was almost the same.

\section{CONCLUSION}

In conclusion, our study revealed that CALT is an important structure of the eye and is responsible for generating a local immune response. However, depending on the age, there are variations in the structural features of CALT, in terms of T, B lymphocytes and lymphoblasts. Existence, diffuse distribution, and accumulation of the main lymphoid cells (T and B lymphocytes) forming Band T-zones of CALT play an important role in the formation of a local immune reaction in the conjunctiva. These findings can be useful for studying the role of CALT in mucosal immunity and especially for future comparative studies of CALT in diseases of the eye and preocular tissues in piglets and pigs.

\section{REFERENCES}

Astley RA, Chodosh J, Caire W, Wilson GM (2007) Conjunctival lymphoid follicles in new world rodents. Anat Rec 290(9): 1190-1194.

Astley RA, Kennedy RC, Chodosh J (2003) Structural and cellular architecture of conjunctival lymphoid follicles in the baboon (Papio anubis). Exp Eye Res 76: 685-694.
Bayraktaroglu AG, Asti RN (2009) Light and electron microscopic studies on conjunctiva associated lymphoid tissue (CALT) in cattle. Revue Med Vet 160(5): 252-257.

Bose T, Lee R, Hou A, Tong L, Chandy KG (2017) Tissue resident memory $\mathrm{T}$ cells in the human conjunctiva and immune signatures in human dry eye disease. Sci Rep 7: 45312.

Chianini F, Majo JN, Dom'tnguez SJ, Domingo M (2001) Immunohistological study of the immune system cells in paraffin-embedded tissues of conventional pigs. Vet Immunol Immunopathol 82(3-4): 245-255.

Franklin RM, Remus LE (1984) Conjunctiva-associated lymphoid tissue: evidence for a role in the secretory immune system. Invest Ophthalmol Vis Sci 25(2): 181-187.

Knop N, Knop E (2008) Conjunctiva-associated lymphoid tissue (CALT) - the physiological protective MALT of the conjunctiva. Acta Ophthalmol 86: 243.

Steven P, Rupp J, Hüttmann G, Koop N, Lensing C et al. (2008) Experimental induction and three-dimensional twophoton imaging of conjunctiva-associated lymphoid tissue. Invest Ophthalmol Vis Sci 49(4): 1512-1517.

Sakimoto T, Shoji J, Inada N, Saito K, Iwasaki Y, Sawa M (2002) Histological study of conjunctiva-associated lymphoid tissue in mouse. Jpn J Ophthalmol 46(4): 364-369.

Tanimoto T, Ohtsuki Y (1996) Evaluation of antibodies reactive with porcine lymphocytes and lymphoma cells in formalin-fixed paraffin-embedded, antigen-retrieved tissue sections. Am J Vet Res 57(6): 853-859.

*Cite this article as: Irgashev A, Kalandarova Z, Ishenbaeva S, Asanova E, Tagaev T, Vityala Y, Vityala S (2021) Immunohistochemical study of conjunctiva-associated lymphoid tissue in piglets and pigs. Explor Anim Med Res 11(2): 173-178. DOI : 10.52635/eamr/11.2.173-178. 